\title{
MEDIOS DE INFORMACION Y PODER: EL CONTROL DE LOS FLUJOS DE INFORMACION *
}

\section{Gurutz Jáuregui Bereciartu}

Universidad del País Vasco

RESUMEN. Este trabajo parte de la consideración de que, en la práctica, la información, en lugar de un derecho, se constituye en un factor de poder, a través de la mutua interrelación dialéctica entre el poder político y los medios de comunicación, marginando así a quiencs teóricamente son su principal protagonista y destinatario: los ciudadanos. Las nuevas tecnologías tienden a agudizar esta situación, pero también pueden favorecer una mayor participación de los ciudadanos en el control de los flujos de información, a través de fórnulas que se indican, haciendo posible el paso de la vigente relación bilateral a una relación triangular medios de información/ciudadanos/poder político.

«El valor de un Estado a la larga es el valor de los individuos que lo componen; y un Estado que pospone los intereses de la expansión y clevación mental de sus individuos, a un poco más de perfección administrativa o a la apariencia que de ella da la prácrica en los detalles de los asuntos; un Estado que empequeñece a sus hombres, a fin de que puedan ser más dóciles instrumentos en sus manos, aun cuando sea para fines beneficiosos, hallará que con hombres pequeños ninguna cosa grande puede ser realizada.»

(John Stuart Mil.t, Sobre la libertad.)

El debate sobre el control de los flujos de información es tan antiguo como los propios medios de información, y ello es lógico en la medida

* La realización de este trabajo ha sido posible gracias a una amable invitación de la Universidad de Nevada (USA), en cuyo Basque Studies Program residi durante el mes de naarzo de 1988, así como a la ayuda financiera otorgada por el Comité Conjunto HispanoNorteamericano para la Cooperación Cultural y Educativa. 
que tal control constituye un elemento clave en la relación dialéctica existente entre la información, los medios de información y el poder. Esta relación está resultando afectada, sin embargo, por la actual revolución tecnológica, y ello hace que el control de los flujos de información aparezca, una vez más, en el ojo del huracán del vigente debate sobre los cambios a operar en el sistema de información. A ello vamos a dedicar este trabajo, y a tal efecto, haremos referencia a cuatro aspectos, a saber: 1) la relación clásica entre el poder, la información y los medios de información; 2) los cambios que se vienen operando como consecuencia de la revolución tecnológica, y su incidencia y efectos en relación al poder; 3) el control de la información y la actual problemática que de él se deriva; 4) el futuro de la relación entre los tres polos citdaos, a través del análisis, de una parte, de los valores que debe perseguir la información, y, de la otra, de los instrumentos mediante los cuales satisfacer y garantizar tales valores.

\section{1) PODER, INFORMACION Y MEDIOS DE COMUNICACION}

El concepto de poder, como habitualmente ocurre con aquellos conceptos que hacen referencia a aspectos fundamentales del ser y la existencia humanos, es extraordinariamente ambiguo, equívoco, y susceptible de numerosas y encontradas definiciones. Dejando al margen disquisiciones teóricas que no vienen al caso, nos interesa establecer un mínimo común denominador capaz de definir el poder en un sentido amplio. Desde tal perspectiva no resulta difícil coincidir en la idea de que se produce un ejercicio del poder «cuando $A$ participa en la adopción de decisiones que afectan a $B$ ».

Existen, si nos atenemos a la forma de ejercitarlo, diversos tipos de poder tales como la coerción, la fuerza, la autoridad, la manipulación o la influencia. Son precisamente estos dos últimos los que interesa reseñar, dada su directa relación con la información y con los medios de información.

La manipulación constituye una forma de poder en la que la obediencia se produce al carecer, quien ha de obedecer, de un conocimiento, bien de la procedencia, bien de la naturaleza exacta de lo que se pide.

$\mathrm{La}$ influencia, por su parte, supone una persuasión racional y sin mediación de conflicto, por parte de $A$ con respecto a $B$. Se ha discutido mucho acerca de si la influencia, tal como acaba de definirse, constituye o no una forma de poder. Aun cuando la cuestión dista mucho de ser susceptible de opiniones unívocas, nos inclinamos por una respuesta afirmativa haciendo propia la opinión de Bachrach y Baratz al indicar que «también se ejerce el poder cuando $A$ consagra sus energías a crear o reforzar aquellos valores sociales y políticos y prácticos institucionales que limitan el alcance del proceso político a la consideración pública solamente de los problemas que sean relativamente inocuos para $A$. En la medida en que $A$ consigue hacerlo, se impide, 
para todos los efectos prácticos, que $B$ ponga sobre el tapete cualquier problema cuya resolución pueda perjudicar seriamente al conjunto de preferencias de $A » 1$.

Qué duda cabe que la información constituye un extraordinario instrumento de poder, tanto desde una perspectiva manipuladora como, sobre todo, como elemento de influencia de los ciudadanos, particularmente en este último caso, en los sistemas políticos democráticos. La información, y en el caso concreto que aquí nos ocupa, la información política, constituye el sistema nervioso de toda unidad política. No se puede olvidar que en los países democráticos la legitimidad se sustenta, sobre todo, en valores de consenso y persuasión, y en tal sentido la actividad política constituye esencialmente una forma de comunicación. Quien persigue la consecución del poder político lo hace mediante la organización de la conducta de los otros, y organización implica de modo indispensable comunicación.

En los sistemas políticos modernos la información se genera y reproduce a través de canales especializados, como son los medios de información o comunicación, de modo que tales medios constituyen elemento inseparable e imprescindible para la transmisión de la información. Pero los medios de información son algo más que un instrumento de transmisión de los flujos de información, constituyéndose en sí mismos en importantísimo centro de poder, cuyas fuentes de dominio radican en sus propietarios, a través de una concentración económica y su integración, bien en manos de semimonopolios, o bien del control público; en la base industrial de la comunicación, es decir, en sus fuentes de producción y diseminación; o incluso, en el propio prestigio o estatus adquirido por los propios medios de información. En consecuencia, no es ya la información en sí, sino los medios informativos quienes constituyen factor determinante para la formación de las actitudes de la opinión pública $y$, consecuentemente, para el tipo de presiones ejercidas por esa opinión pública sobre los centros de decisión de poder.

El carácter de los medios de información como centros de poder se manifiesta en el hecho de que los mismos son agentes de quienes ejercitan algún poder político o económico, y aun cuando tales medios pueden ejercitar potencialmente un poder independiente, en realidad casi nunca actúan independientemente. Tal realidad práctica choca en todo caso y de manera indefectible con una declaración de principios que no sé si denominarla ingenua o cínica, según la cual todos los medios de información, sin excepciones, se declaran independientes.

En tal sentido, los medios de información tienen un carácter autónomo con respecto a la información en sí, resultando incluso más importantes que aquélla. Se origina así una situación de endogamia en la que la información

${ }^{1}$ Peter Bachrach y Morton S. Baratz, Power and Powerty. Theory and Practice, Nueva York, Oxford University Press, 1970; citado por Steven Lukss, El Poder. Un cnfoque radical, Madrid, Siglo XXI, p. 11. 
se reduce a un juego dialéctico entre el poder político y el poder de los medios de información, reduciendo a un papel de mero convidado de piedra a quien constituye el destinatario y sujeto principal de tal información, es decir, a los ciudadanos. Sin embargo, la información, entendida como elemento de poder, no se debe agotar en la mutua interrelación poder político/ medios de comunicación, sino que tiene un carácter triangular cuyos vértices son el poder político, los medios de información y los ciudadanos.

\section{2) LA REVOLUCION TECNOLOGICA Y SU INCIDENCIA EN LOS MEDIOS DE INFORMACION. ALGUNAS CONSECUENCIAS}

El mundo de la comunicación está sufriendo una importantísima transformación como consecuencia de la revolución tecnológica iniciada hace unos años, y cuyo alcance, desarrollo y efectos, así como consecuencias para el futuro de nuestra sociedad, estamos todavía muy lejos de imaginar. (Interesa precisar que estas transformaciones afectan a los medios de comunicación entendidos en sentido amplio, y no sólo a los medios de información. La comunicación, entendida en tal sentido amplio, implica tanto al emisor cuanto al receptor y abarca medios tan heterogéneos como la prensa, la radio, la TV, el cine, los libros y las revistas, la educación, el correo, el teléfono, los sistemas de télex, telefax, ordenadores, transmisión de datos, etc. En este trabajo nos centramos de modo particular en el mundo estricto de la información sin perjuicio de ocasionales referencias al campo más amplio de la comunicación. En todo caso, como se verá después, el ámbito de la información constituye todavía una parte predominante dentro del conjunto de la comunicación.) A expensas de los cambios que vayan a operarse en los próximos años, y teniendo en cuenta el momento actual que puede definirse como de período de transición entre los «viejos» y los «nuevos» medios de información, parece oportuno destacar algunos rasgos, o si se quiere algunas líneasfuerza por ahora dominantes en el vigente sistema de información, las cuales pueden quedar afectadas, bien en sentido positivo o negativo, por las nuevas tecnologías.

1. El primer rasgo es el que se refiere al extraordinario crecimiento de los flujos de información. De un estudio empírico realizado por varios profesores norteamericanos y japoneses sobre los flujos de información de ambos países $^{2}$, se deducen los siguientes datos:

En Estados Unidos el crecimiento del número de palabras suministradas por el conjunto de los medios de comunicación en el período 1960-1980

2 Ithiel de Sola Pool, Hiroshi Inose, Nozomu Takasaki y Roger Hurwitz, Communication Flows, North-Holland/University of Tokyo Press, 1984, pp. 16 y ss. 
ha sido muy superior $(8,4$ por 100$)$ al crecimiento, durante el mismo período, del Producto Interior Bruto (3,7 por 100). En Japón, durante el período 1960-1975, el crecimiento ha sido similar al Producto Interior Bruto. Ello ha originado que el número de palabras suministradas por los medios de comunicación americanos ascendiera, en 1980, a la cifra de casi 11 millones de palabras por día, mientras que en Japón oscilaba, en 1975, en torno a 1.500 .000 palabras diarias.

El crecimiento no ha sido igual en todos los medios de comunicación, y en tal sentido cabe destacar el predominio casi exclusivo de la radio y la TV. Así, en Estados Unidos, en 1960, la radio y la TV suministraban el 92 por 100 del total de la información, ascendiendo tal porcentaje a casi el 98 por 100 en 1980. En Japón las cifras eran del 84 y del 91 por 100 en 1960 y 1975, respectivamente.

Tal explosión en el suministro de información no se ha correspondido, sin embargo, con un crecimiento similar en el consumo de las palabras. Así, en 1980, en Estados Unidos el consumo medio de palabras por individuo y día era del orden de 48.000 , y en Japón, en 1975 , de 23.000 palabras.

Tal crecimiento ha sido posible como consecuencia del abaratamiento de los costes. En Estados Unidos, en 1980, el coste de transmisión de 1.000 palabras a través de la radio ascendía a 0,0002 centavos, y a través de la TV, 0,002 centavos. Los costes de transmisión de palabras en los periódicos y los libros eran 30 y 400 veces más caros que en la TV.

2. El abaratamiento de costes hace referencia al aspecto concreto de la transmisión de la información, y constituye consecuencia directa del avance tecnológico. Pero la posibilidad de poder emitir información a tan bajo coste exige con carácter previo una importante inversión en equipos de alta tecnología, así como toda una estructura financiera poderosa capaz de mantener una red capilar de distribución de información desde el lugar en que se genera hasta llegar al domicilio del receptor de la información. De ello se deriva un segundo rasgo o consecuencia de la revolución tecnológicà informativa, cual es la concentración de la información en manos de núcleos muy reducidos de personas o empresas. Resulta extraordinariamente gravoso el desplazamiento, equipamiento y mantenimiento de corresponsales en el extranjero, por lo que muy pocos medios se hallan en condiciones de establecer una red propia de información. Ello origina que la práctica totalidad de los medios de información dependan en mayor o menor grado de los servicios de las cinco grandes agencias internacionales de prensa, situación que se reproduce a escala interna con respecto a las diversas agencias informativas nacionales.

Por esta razón el futuro de la comunicación se debate cada vez más en la pugna entre dos tipos de monopolios, cuales son el monopolio político ejercido por los diversos Estados — modelo hasta ahora dominante en Europa 
Occidental y actualmente en franca crisis--, y un monopolio derivado de la concentración económica en la lucha entre las diversas fuerzas del mercado, particularmente las grandes empresas transnacionales. La influencia de los grandes monopolios se manifiesta no sólo en el ámbito económico y tecnológico (por ejemplo, cabe reseñar que IBM consiguió en 1983 unos ingresos brutos de 23,3 billones de dólares como consecuencia de las ventas, a través de todo el mundo, de sus productos relacionados con el ámbito de los sistemas de información, equipamiento y servicios) ${ }^{3}$, sino también en el social y cultural. Es evidente que el sistema global de comunicaciones refleja cada vez más no los modos y valores de las sociedades individuales, sino los de un club muy exclusivo con una tasa de ingresos muy alta, muy pocos miembros y excepcionales beneficios.

3. Esta «colonización» sociocultural operada por los medios de información viene facilitada como consecuencia - y he aquí el tercer rasgo definidorde la unilinealidad de los flujos de información. Ya se ha indicado antes que el suministro de información supera en grado incomparable al consumo de la misma, y ello implica la imposibilidad de una actitud activa por parte del receptor de la información. La capacidad de autonomía del receptor queda limitada en la práctica a la elección entre los diversos medios de in. formación a su alcance o, en su caso, a la alternativa última del OFF o el ON. Es cierto que existen diversos impouts por parte del receptor, tales como contactos individuales con los televidentes, resultados de los indices de audiencia o lectura en su caso; evidencia o no de las ventas, cartas, llamadas, por parte del público, etc. Pero, en realidad, todo ello deriva, como consecuencia a la vez de la dispersión y falta de organización de la audiencia y de la capacidad de poder de los medios de información, en una relación en la que los contactos son dirigidos y controlados por los medios de información. De tal modo, resulta evidente que los medios de información, en lugar de controlar las instituciones sociales, dependen de ellas, y el público, en lugar de controlar a los medios, depende de ellos.

4. El cuarto y último aspecto a destacar es la uniformización de los mensajes emitidos, uniformización que no responde en absoluto a la variedad reflejada en la sociedad. Se trata de una consecuencia directamente derivada de las dos anteriores. Se reciben sólo determinadas informaciones, y tal recepción es acrítica, al menos socialmente, en tanto en cuanto los receptores individualizados de la información carecen de medios para comparar y estructurar un criterio colectivo. Se produce así una pérdida de la autonomía individual que, en cierto modo, es consecuencia de la propia evolución tecnológica de los medios de difusión, pero al mismo tiempo se trata de una consecuencia

${ }^{3}$ Dato recogido de Marjorie Ferguson, New Communication Technologies and the Public Interest, Londres y Beverly Hills, Sage Publications, 1986. 
conscientemente buscada por el propio sistema a través de un proceso de integración de las manifestaciones de oposición al mismo. Se da un proceso en el que, desde arriba, la autoridad o el poder identifica o asimila, y desde abajo, los individuos, la gente en general, identifica o imita. De acuerdo con ello se emiten mensajes de integración que hacen ver lo diferente como no conveniente, en tanto que resulta no acorde con las pautas marcadas por los poderes homogeneizantes. En tal sentido, el mundo de la comunicación se ha convertido en un espacio privilegiado para la neutralización de lo político. un universo en el que los conflictos de interés, las relaciones de fuerzas, los problemas sociológicos, etc., deben estar ausentes.

Las nuevas tecnologías están produciendo una modificación de las propias formas a través de las cuales se produce el tráfico de información, y ello puede traer como consecuencia que algunos de los rasgos ya citados resulten afectados de forma importante en un futuro no muy lejano.

Bordewijk y Van Kaam han establecido cuatro modelos distintos de tráfico de información atendiendo a dos parámetros básicos cuales son el archivo de información, que puede ser central o individual, y el control del tiempo y selección del objeto, que también puede ser central o individual. Según la interrelación que se produzca entre estos parámetros, los citados autores establecen cuatro diferentes tipos de información, a saber: alocución, registro, consulta y conversación ${ }^{4}$.

\section{Los cuatro modelos del tráfico de información}

\begin{tabular}{|c|c|c|}
\hline & \multicolumn{2}{|c|}{ Arcbivo de la información } \\
\hline & Central & Individual \\
\hline $\begin{array}{l}\text { Control del tiempo y selección del abjeto cenral ... } \\
\text { Control del tiempo y selección del objeto: individual. }\end{array}$ & $\begin{array}{l}\text { Alacurián } \\
\text { Consulta }\end{array}$ & $\begin{array}{l}\text { Registro } \\
\text { Conversación }\end{array}$ \\
\hline
\end{tabular}

\section{Definiciones}

Alocución: La transmisión simultánea de una oferta de información centralmente constituida y para la que se pretende una inmediata atención, de acuerdo con un esquema horario centralmente determinado.

Conversación: Intercambio entre individuos de la información que ellos disponen, de acuerdo con un esquema horario mutuamente convenido.

4 J. L. Bordewrjk y B. van KaAm, Allocutie, Baarn, Netherlands, Bosch and Keuning, 1982. Seguimos aquí la adaptación de este esquema realizada por Denis McQuall, en «Is Media Theory Adequate to the Challenge of the New Communications Technologies?», en Marjorie Ferguson, op. cit., pp. 8 y ss. 
Consulta: Consulta selectiva por parte de individuos de un archivo central de información, durante los períodos y momentos determinados por cada individuo.

Registro: La acumulación en un archivo central de información disponible para participantes individuales, de acuerdo con un control del tiempo y una selección del objeto centralmente determinados.

La alocución constituye la forma de comunicación típica de los «viejos» medios de información cuales son la radio y la TV. En efecto, se trata en este caso de un modelo de comunicación en el que el «almacén» central suministra información a muchos receptores individuales durante las horas y mediante los contenidos determinados por la propia fuente de información.

La consulta constituye también una vieja forma de comunicación, y su ejemplo más típico lo constituyen las bibliotecas. La prensa escrita tiene, por su parte, caracteres tanto de alocución como de consulta. El modelo «conversación» también tiene una cierta tradición, particularmente a través del servicio postal y el teléfono, mientras que el modelo «registro» apenas ha tenido entidad propia entre los sistemas de información clásicos.

De acuerdo con las perspectivas que nos ofrece la vigente revolución tecnológica, parece evidente que los nuevos medios de comunicación tienden a incrementar las posibilidades de la consulta (a través de la telemática, la TV por cable y el vídeo), la conversación (a través de los cables interactivos, la radio y la interconexión de sistemas informáticos) y el registro (a través del archivo informatizado de todos los servicios de los medios de información conectados a un determinado sistema).

¿En qué medida va a quedar afectado el sistema de información como consecuencia de los cambios que comienzan a operarse en los diversos modelos a través de los cuales se produce el tráfico de información? $\mathrm{Y}$, sobre todo, ¿qué efectos van a producir estos cambios en la información y en los medios de información desde la perspectiva del poder? La respuesta resulta ciertamente difícil, y en no pocos casos ambivalente, en función de una serie de factores a los que se aludirá más adelante.

El crecimiento de los flujos de información constituye, a priori, un dato positivo, pues implica un aumento de las posibilidades de selección de la misma por parte de los individuos, facilitando de esta forma un aumento de la libertad individual a la hora de obtener la información. También resulta positiva la desproporción existente entre el suministro y el consumo de información. A mayor desproporción, mayores posibilidades de selección, siempre que el suministro de información provenga de fuentes diversas. El aspecto negativo del crecimiento de los flujos de información reside en que una parte abrumadoramente mayoritaria del suministro de la información se genera a través de la radio y la TV, lo que supone un predominio casi absoluto del 
modelo de alocución sobre los otros modelos. No obstante, y como ya se ha indicado más arriba, se manifiesta una tendencia favorable a los otros modelos en un futuro no muy lejano.

La concentración constituye uno de los elementos más negativos del vigente sistema de información. Además, el desarrollo tecnológico está provocando una acéleración evidente de ese proceso de concentración en su doble perspectiva técnico-económica y estrictamente informativa. Por ello, resulta previsible no sólo el mantenimiento de un sistema altamente concentrado, sino incluso su intensificación hasta niveles insospechados. Si no se establecen medios de control efectivo y adecuados, la concentración de los medios de información y, consecuentemente, de la propia información en manos de monopolios poderosos puede hipotecar de forma muy grave el sistema de información del futuro. Por mucho que se desarrollen modelos de información individuales no dependientes de archivos centrales, ello no impedirá un control casi total del sistema de información por parte de unos pocos centros de poder. Constituyendo éste uno de los aspectos cruciales de los sistemas de información, y dada su íntima conexión con el factor poder, se incidirá ampliamente sobre él a la hora de abordar el problema del control de los flujos de información.

Las nuevas tecnologías pueden afectar a la unilinealidad de la información en un sentido ambivalente. Todo dependerá del mayor o menor desarrollo de los diversos modelos de información. En todo caso, y desde un punto de vista estrictamente técnico, la impresión es que durante un tiempo relativamente largo no variará tal unilinealidad, y que incluso aumentará más, si cabe, tal tendencia. La lejanía y anonimato de los centros emisores de información, como está ocurriendo ya en los sistemas de televisión por cable; la dispersión de su audiencia, con lo que ello implica en cuanto a imposibilidad de contactos entre los receptores de la información; la inexistencia de un referente crítico que nos permita calibrar y comparar nuestra opinión con la de otros receptores, como sucede actualmente con las TV nacionales o regionales, cuya programación y política informativa se halla sujeta a una crítica importante por parte de la opinión pública, etc., están originando un aumento del aisiamiento de los receptores de la información, una disminución de su capacidad de discernimiento $\mathrm{y}$, en definitiva, una peligrosa anomia que puede conducirnos a las peores consecuencias.

En contraposición, el desarrollo de otros medios de información tales como los diversos sistemas de comunicación por cable, o la informática, pueden originar un aumento de los inpouts por parte de los individuos, particularmente en los modelos de conversación, consulta y registro. Todo dependerá, como ya se ha indicado, del desarrollo de cada uno de los diversos modelos.

Por último, la uniformización ofrece, también, un carácter ambivalente. La intensificación de la concentración de los medios de información originará un considerable desarrollo de la uniformidad. Asimismo, el carácter supra- 
nacional de ciertos centros emisores que se ven obligados a dirigirse a una audiencia absolutamente dispar, originará o, más exactamente, intensificará la aparición de valores, modelos y pautas culturales estándar, en detrimento de la diversidad cultural de los receptores de la información. La universalidad de la cultura constituye en sí un valor positivo, siempre que la misma sea realmente universal, y no el reflejo del dominio de unas culturas sobre otras, lo que origina una prevalencia de aquéllas no tanto por sus valores intrínsecos, cuanto por su carácter precisamente dominante. En cuanto a los factores positivos, cabe destacar el previsible crecimiento de los medios de información de carácter local o regional. Tal aumento va a obedecer a dos tipos de causas: unas, estrictamente tecnológicas, derivadas del propio desarrollo de la técnica, facilitando así el surgimiento de tales medios de comunicación, y otra, sociológica, derivada de la necesidad de mantener un cierto grado de conciencia colectiva frente a la anomia provocada por los otros medios. Por último, en la medida en que se desarrollen los modelos de comunicación de mutua interrelación y se produzca una disminución de la unilinealidad, puede producirse asimismo un aumento de la diversidad.

En contra de una posible interpretación en sentido contrario, interesa sobremanera afirmar que la inclinación definitiva de tales efectos ambivalentes en un sentido positivo o negativo no es algo que depende de la evolución tecnológica futura, sino de nuestra actitud y respuesta frente a la misma. Ello se manifiesta de modo evidente a la hora de determinar qué tipo de controles cabe establecer sobre la información, si es,que realmente procede establecer alguno.

\section{3) EL CONTROL DE LOS FLUJOS DE INFORMACION. INSUFICIENCIA DE LAS TEORIAS CLASICAS}

La política reguladora de la información ha venido determinada en los diversos países en función de los diversos valores en los que vienen sustentándose los respectivos sistemas políticos. Dejando al margen otras áreas geográficas, y centrándonos de modo exclusivo en el mundo occidental, cabe recordar algo de todos conocido, cual es la existencia de dos grandes corrientes de opinión, en cierto modo antagónicas, dominantes en Estados Unidos y Europa Occidental, respectivamente. Se trata de las teorías de la libre información y de la responsabilidad social.

La primera de las corrientes, dominante durante más de treinta años en los Estados Unidos, propugna, o cuando menos propugnaba hasta hace muy poco tiempo, una libertad de flujos prácticamente total. La ausencia de controles importantes sobre los medios de comunicación, añadida a la enorme potencialidad económica de los mismos, les ha permitido inundar el mercado 
mundial con sus programas y su «cultura» y ha favorecido una adaptación perfecta a la nueva situación hasta el punto de contar actualmente con un equipamiento y unos medios tecnológicos extraordinarios que aseguran aún más su dominio mundial en el futuro.

La teoría de la libre información adopta como principio básico la idea de que todo individuo debe ser libre para mantener sus opiniones, expresarlas públicamente, y a tal efecto, reunirse y organizarse con otros. Constituye tal teoría una expresión de los principios y valores del Estado liberal que, como de todos es conocido, se basa en la creencia de la supremacía del individuo, de la razón, de la verdad y el progreso y, en definitiva, de la soberanía y voluntad populares.

Esta teoría de la libre información ha tenido efectos prácticos muy diversos si atendemos a la doble vertiente de toda política de la información cual es, de una parte, la libertad de informar y, de otra, el derecho a la información. En cuanto a la libertad de informar, la solución práctica ha consistido en evitar el establecimiento de mecanismos de censura previa, de modo que sean las leyes las que determinen, a posteriori, cualquier responsabilidad derivada de la colisión con otros derechos individuales o con las demandas legítimas de la sociedad.

Mucho más problemática ha resultado la regulación del derecho a la información. En no pocas ocasiones, la teoría de la libre información ha venido a identificarse con el derecho de propiedad, y ha sido considerada como el derecho a poseer y usar los medios de comunicación sin límites o interferencias por parte del gobierno.

Frente a la teoría de la libre información, y a tenor de la evolución del Estado liberal de Derecho en Estado social de Derecho, surge en Europa, particularmente, a partir de la segunda guerra mundial, la teoría de la responsabilidad social. Esta teoría considera que los medios de comunicación deben ser objeto de público control, pues constituyen instrumentos de servicio público comparables a los demás del Estado del bienestar, en la medida en que cumplen funciones informativas, culturales, educativas, etc.

La teoría de la responsabilidad trata de reconciliar la independencia con las obligaciones hacia la sociedad, y se fundamenta en la prevalencia del principio de igualdad sobre el principio de libertad. El desarrollo tecnológico y comercial de los medios de información origina la limitación de posibilidades de acceso para los individuos y para ciertos grupos y permite el aumento de poder de determinados grupos o sectores económicamente poderosos. En la medida en que los medios de información tienen un carácter de servicio público se deben establecer reglas que hagan posible el cumplimiento de las obligaciones de ello derivadas.

A tal efecto se han previsto dos tipos de fórmulas, cuales son, de una parte, la creación de instituciones públicas, pero independientes, para el go- 
bierno de los medios de radiodifusión, medida que ha supuesto un importante reforzamiento del concepto de responsabilidad social y, de la otra, un mayor desarrollo de la profesionalidad como medio de consecución de una mejor calidad, permitiendo al mismo tiempo a los propios medios fórmulas de autorregulación. Esta teoría de la responsabilidad social se ha manifestado de modo particular en los medios de radiodifusión y ha supuesto que por parte de los gobiernos se hayan adoptado medidas que, al menos formalmente, contravienen los principios en los que se sustenta la libertad de información. Así, se han establecido fórmulas diversas de intervención legal o fiscal, o incluso, se ha limitado o prohibido la titularidad privada de determinados medios de difusión, como la televisión, todo ello con el ánimo de obtener determinados objetivos sociales, o de limitar los efectos de las tendencias y presiones del mercado.

Actualmente, la idea de la propiedad privada de los medios de producción como panacea y garantía del derecho a la libre información es simplemente absurda. Es cierto que la teoría de la libre información supuso en su momento un avance extraordinario en lo referente a la libertad de informar mediante la exigencia de la supresión de cualquier tipo de censura previa. No es menos cierto que tal libertad de información se halla sometida, todavía, a fuertes embates, no sólo en los países no democráticos, sino también en los países democráticos avanzados, y que por ello resulta del todo preciso mantenerse vigilantes y recurrir a ciertos viejos principios del Estado liberal, los cuales mantienen toda su vigencia.

Pero no es menos evidente que, en las circunstancias presentes, tal teoría resulta manifiestamente insuficiente, y no ofrece solución alguna a la otra perspectiva del derecho a la información cual es el derecho a recibir información. La teoría de la libertad de flujos de información implica de hecho un sistema de protección exclusiva de los derechos de los propietarios de los medios, que no encuentra similar expresión en otro tipo de derechos de otros colectivos tales como los propios periodistas, la audiencia, o los posibles beneficiarios o víctimas de la libre información.

En la actualidad, el concepto de la libre información o, si se quiere, la filosofía del libre flujo de información, supone, en la realidad, una situación en la que la teórica «prensa libre» ha devenido en arma ideológica del sistema capitalista y de los monopolios económicos y, consecuentemente, en instrumento privilegiado de la reproducción y mantenimiento de los intereses y objetivos por ellos perseguidos. La defensa de la libertad de los flujos de información constituye una auténtica falacia, si tenemos en cuenta que la práctica totalidad de la información mundial se halla monopolizada por cinco grandes agencias de noticias (Associated Press-AP, United Press InternationalUPI, Reuter, Agence France Press-AFP, y Telegrafnoye Agentsivo Sovietskovo Soyuzo-TASS), las cuales controlan la práctica totalidad de los flujos de 
información generados en cualquier parte del globo, a lo que se debe añadir, más recientemente, los diversos sistemas de transmisión vía satélite ${ }^{5}$.

Al igual de lo que ocurría en el caso anterior, la teoría de la responsabilidad social ha supuesto un importante avance en lo que respecta a la garantía del acceso a la información por parte de todos los ciudadanos, y al establecimiento de fórmulas dirigidas a paliar la desigualdad a la hora de ejercer el derecho a la información. A pesar de ello, esta teoría se halla sujeta actualmente a una fuerte crítica, derivada tanto de las desviaciones de la que ha sido objeto en la práctica, cuanto de su incapacidad para responder adecuadamente a la nueva situación derivada del cambio tecnológico.

De una parte, no cabe olvidar que, en no pocas ocasiones, el control que se ha ejercido sobre determinados medios de radiodifusión por parte de los sucesivos gobiernos, particularmente en aquellos países en los que se ha mantenido un monopolio público de la televisión, ha distado mucho de ser objeto y neutral. La televisión, al igual que anteriormente la radio, fueron considerados desde sus inicios como instrumento de poder de primer orden, y en tal sentido en la práctica totalidad de los países de Europa Occidental, en mayor o menor grado, se han producido situaciones flagrantes en las que el teórico interés general ha sido confundido-identificado con el interés particular del correspondiente gobierno de turno. De este modo, un instrumento que teóricamente debiera haber servido para paliar la influencia de los grupos económicos de poder dominantes en los medios de información privados, se ha convertido en la práctica en un monopolio más a añadir a los anteriores, provocando con ello una disminución de las garantías de objetividad y neutralidad exigibles a los medios de información.

El semimonopolio de los medios de información, y en algunos casos el monopolio absoluto de algunos de los medios más influyentes, como la televisión, por parte del Estado han supuesto una efectiva disminución de las garantías del derecho a la información, particularmente en períodos de crisis, y un sobredimensionamiento del valor seguridad sobre el valor libertad.

Por último, la teoría de la responsabilidad social se ha manifestado incapaz para resolver uno de los problemas que constituyó la razón fundamental de su aparición, cual es la fijación de límites a la acción de los grandes monopolios económicos, en parte por su defectuosa aplicación, y en parte por las transformaciones operadas como consecuencia de la revolución tecnológica. Actual-

Puede obtenerse una información actualizada del ámbito de actuación de estas agencias, así como de los diversos sistemas de satélites, en Thomas L. MCPHaIL, Electronic Colonialism, Londres, Sage, 1987, pp. 152 y ss. Esta situación de monopolio ha sido duramente denunciada, como es bien sabido, por parte de los países en vías de desarrollo. Las objeciones planteadas por estos países son, principalmente, tres: 1) la orientación mercantilista y comercial de los medios de comunicación occidentales; 2) la unilinealidad del flujo de información, proveniente fundamentalmente de EE.UU., con casi ninguna reprocidad por parte de otros países, y 3) la dominación cultural, o lo que se ha dado en llamar el «colonialismo electrónico». 
mente, la pretensión de los Estados nacionales de establecer límites al libre flujo de información resulta prácticamente inviable en la práctica, habida cuenta la transnacionalización de los sistemas de transmisión de la información (televisión vía satélite, etc.).

$Y$, sin embargo, la teoría de la responsabilidad social sigue resultando en el momento actual tanto o más necesaria que hace unas décadas. A mayor oligopolización del sistema de información, mayor necesidad de establecer controles efectivos con el objeto de que la información mantenga su carácter de servicio público en interés del conjunto de la sociedad, y de evitar situaciones de colonización informativa y cultural ${ }^{6}$.

De cuanto acaba de indicarse se deduce que los viejos sistemas reguladores de los flujos de información resultan claramente insuficientes para responder a la problemática actual, por lo que se hace imprescindible la búsqueda de fórmulas alternativas que, sin dejar de recoger los aspectos positivos de aquéllas, permitan superar sus insuficiencias. El problema es ciertamente arduo pero no irresoluble.

\section{4) MEDIOS DE INFORMACION Y DEMOCRACIA PARTICIPATIVA}

El primer obstáculo con el que nos enfrentamos a la hora de establecer sistemas alternativos dirigidos al control efectivo de los medios de información, es el relativo a lo que podemos definir como el determinismo tecnológico que constituye una idea cada vez más arraigada en nuestra sociedad. El determinismo tecnológico, al igual que otro tipo de determinismos vigentes en la sociedad contemporánea, no es sino el reflejo de esa concepción materialista $o$, si se quiere, mecanicista de la historia, dominante en el mundo

"Cuando hablamos de «colonialismo electrónico» no sólo nos referimos a la situación de los países en vías de desarrollo, sino también a los países desarrollados del mundo occidental. Un país económicamente desarrollado puede ser perfectamente subdesarrollado en materia de comunicación. Ejemplos concretos de tal subdesarrollo los tenemos en los casos de Australia y Canadá. Este últımo país ha tratado, por razones obvias, de establecer un sistema de protección, hasta el punto de que la CBC (Canadian Broadcasting Corporation) realizó hasta 1983 un titánico esfuerzo en favor de la promoción de una producción nacional propia, que fracasó irremisiblemente. En el citado año de 1983, el 76 por 100 de los programas seguidos por la población de habla inglesa era de origen «extranjero», particularmente EE.UU. (Datos of recidos por el propio Departamento de Comunicaciones del Gobierno Federal de Canadá, y recogidos en Marjorie Ferguson, op. cit., p. 60. También puede verse un amplio informe de esta situación de dependencia canadiense con respecto a los medios de comunicación de EE.UU. en Thomas L. MCPraIL, op. cit., pp. 26 y ss.) La situación comienza a ser bastante parecida en el conjunto de los países de Europa Occidental, en los que el porcentaje de programas de TV importados va (en 1983) desde un 15 por 100 , en el caso de Gran Bretaña, hasta un 43 por 100 , en los casos de Dinamarca y Austria, porcentaje que aumenta sensiblemente en el caso de la importación de filmes, cue va desde un 30 por 100 , en Alemania, hasta un cien por cien, en Holanda. Véanse datos concretos en Denis McQuail y Karen Siune (eds.), New Media Politics, Londres, Sage, 1986, p. 137. 
actual, tanto en los sistemas capitalistas como socialistas. El determinismo constituye quizá uno de los más importantes fundamentos de la filosofía capitalista que han pasado sin solución de continuidad - de forma natural y sin rupturas- a constituir el acervo filosófico del marxismo. A través de la idea del materialismo dominante, tanto en la ética del capitalismo como en la filosofía marxista, se ha producido una reducción de la actividad humana a una mera actividad económica, otorgando a la idea de productividad, de obtención de resultados, de generación de riqueza, un valor primordial dentro de nuestra sociedad. De este modo el individuo, motor de un microcosmos a su medida en donde se manifiesta toda su creatividad, la cual constituye precisamente la victoria del ser humano como ser racional, es sustituido por un tipo universal, abstracto, estándar, elemental y bloqueado, simple pieza de un vasto mecanismo.

Así como no se puede admitir la existencia de una dependencia determinista de la actividad humana con respecto a las relaciones económicas, tampoco es admisible el condicionamiento de las relaciones humanas a unas hipotéticas nuevas relaciones derivadas de los avances tecnológicos. A pesar de nuestra incapacidad para predecir, por ahora, el desarrollo y avance de la revolución de las telecomunicaciones, no parece arriesgado afirmar que la misma va a producir importantes transformaciones sociales. Lo que parece menos evidente es que las nuevas tecnologías tengan que ser, necesariamente, el instrumento a través de las cuales tales transformaciones van a resultar afectadas intencionada o no intencionadamente, y menos que se conviertan en fines en sí mismas.

De ahí la necesidad de relativizar tal determinismo. La tecnología constituye un instrumento en manos de los seres humanos, y en lo que aquí nos interesa aparece ligada a factores sociales, económicos y políticos. Quién actúa, en qué dirección, para qué intereses o con qué fines; todos estos factores afectan a la capacidad de los nuevos instrumentos tecnológicos para actuar en beneficio o detrimento de los diferentes grupos sociales, a las vías de aplicación, a la estructura de los controles institucionales sobre las mismas, etcétera.

En contra de cièrta visión determinista-pesimista de los avances tecnológicos, es preciso recordar que el peligro no radica en la «pesadilla» electrónica, sino en el comportamiento humano. No en los ordenadores, sino en las decisiones políticas que amenazan la sociedad. Como muy bien afirma De Sola Pool, la censura que siguió a la imprenta no era implícita al proceso de Gutenberg, sino que era una reacción frente a él. De igual modo, la regulación de la comunicación electrónica no es algo implícito a su tecnología, sino una reacción frente a ella. Ordenadores, teléfonos, radio, satélites, son tecnologías de la libertad, tanto como lo fue la imprenta ${ }^{7}$. Como ya indicábamos al

7 Ithiel dE Sola Pool, Technologies of Freedom, Harvard University Press, 1983, p. 226. 
hablar de los diferentes modelos de comunicación, y como se reseñará luego, no hay razones objetivas para pensar que las nuevas tecnologías puedan resultar negativas per se para el desarrollo de la libertad y dignidad humanas. Al contrario, todo induce a pensar que pueden suponer un instrumento enormemente positivo, si realmente se produce una utilización correcta de las mismas. A tal fin, parecen imprescindibles dos condiciones básicas cuales son: a) el establecimiento de un código de valores adecuado a las necesidades de la sociedad contemporánea, en los que sustente toda su actuación, y $b$ ) el desarrollo de medidas e instrumentos capaces de garantizar esos valores y fines perseguidos.

\section{a) Principios básicos de actuación de los medios de información}

Los valores fundamentales exigibles a todo medio de información pueden reducirse a cinco grandes principios: independencia, igualdad, solidaridad, objetividad y diversidad, los cuales no constituyen sino el reflejo de los valores básicos en los que debe sustentarse toda sociedad democrática. Tales principios aparecen intimamente interrelacionados, lo que hace que en no pocas ocasiones tengan que establecerse limitaciones mutuas entre ellos. A la hora de su observancia lo realmente importante no es la consecución o la preferencia de uno de tales valores sobre los otros, sino una equilibrada aplicación de conjunto con el objeto de ofrecer una información adecuada.

- La independencia, entendida en su doble sentido de libertad de informar y de ausencia de obstáculos para ejercer el derecho a la información, constituye el principio primordial en que se han basado los medios de comunicación modernos. Este principio ha ayudado a legitimar la expansión y diversificación de todo tipo de actividades informativas, y ha constituido la base para oponerse a los usos paternalistas, autoritarios y manipuladores de los medios de información, o su interferencia por parte del Estado u otros centros de poder, políticos, económicos, religiosos, etc.

Existe una larga tradición, tanto en la doctrina como en la jurisprudencia comparada, en el sentido de considerar la libertad de información como una libertad preferente, a la que se le dota de un núcleo resistente y constitucionalmente indeclinable, aun cuando choque con otros derechos constitucionalmente reconocidos. Tal preferencia se fundamenta en el hecho de que la libertad de información constituye un presupuesto imprescindible para la existencia del propio sistema democrático ${ }^{8}$.

* Para un análisis de la regulación del derecho a la libre información, tanto en el derecho comparado como español, puede consultarse Santiago Muñoz Machado, Libertad de prensa y procesos por difamación, Barcelona, Ariel Editorial, 1988; particularmente, capítulos II y III. 
Como ya ha quedado indicado en el apartado anterior, tal libertad de información no tiene carácter absoluto, y se halla limitada, en su doble vertiente de derecho a la información y de libertad de informar, por el carácter de servicio público de la información y por la colisión en determinados casos concretos con otros derechos que pudieran resultar lesionados.

- La igualdad, entendida como una correcta distribución de los bienes culturales e informativos que la comunicación ofrece, y que permita el acceso de todos los ciudadanos a la información, tanto en su calidad de emisor como de receptor de tal información. El adecuado cumplimiento de este principio exige que, por parte del ordenamiento jurídico, se adopten disposiciones tanto positivas -estableciendo reglas de acceso para todos los ciudadanos o grupos- como negativas — fijando normas limitadoras de previsibles situaciones de desigualdad, tales como una legislación antimonopolio, etc.

- La solidaridad, entendida en el sentido de favorecimiento de la comu. nidad, y en la defensa de los valores de cooperación, integración, no aislamiento, etc. Se trata, en definitiva, en la asunción y defensa de los valores globales de una saciedad. Ahora bien, pocos valores han sido objeto de interpretaciones falsas e interesadas como éste que nos ocupa. La defensa de los valores de una sociedad determinada implica la búsqueda del interés general del conjunto de sus ciudadanos, que no se identifica con este o aquel interés particular, y que, en modo alguno, tiene que resultar coincidente con la interpretación que los gobernantes otorgan a tal interés general.

Habida cuenta la práctica generalizada de los gobiernos democráticos contemporáneos que, confundiendo el interés general con su propio interés o al menos con la interpretación por ellos efectuada de tal interés, pretenden implicar a los ciudadanos en campañas dirigidas al silenciamiento de las minorías disidentes, se hace preciso delimitar con claridad el sentido de tal solidaridad. La democracia, en contra de lo que tantas veces se afirma, no está fundamentada en el consenso, sino precisamente en el disenso. El único con. senso exigible en democracia es el del respeto a las reglas del juego por parte de los competidores. A partir de ahí, lo fundamental es la existencia de desacuerdos. La democracia implica o debe implicar el derecho real a mantener y defender lo alterno, lo diferente, lo irreducible, lo minoritario, y tal defensa no implica sino una aportación más al conjunto de valores en los que se debe fundamentar la colectividad entera. Frente a las actuales sociedades democráticas que acentúan el consenso, pero a base de mantener las desigualdades y de integrar colectividades pasivas y alienadas es preciso oponer lo que Etzioni ha calificado como las sociedades activas. No es flexibilidad lo que falta a las sociedades democráticas, sino sensibilidad ante las demandas de los «marginados».

El papel de los medios de información en el ámbito de la defensa de la solidaridad entendida como resultante de los diversos disensos, es realmente primordial. Como se verá al analizar los valores de objetividad y diversidad, 
resulta consustancial a los medios de información una tendencia, en muchos casos involuntaria, a desviarse de la realidad. Y tal desviación favorece en la mayor parte de los casos a las tendencias dominantes en el seno de la propia sociedad. Efectivamente, la concentración de los medios de información sobre relativamente pocos asuntos, y tan sólo ciertos aspectos de esos asuntos, llevan generalmente a la gente a percibir tales aspectos y asuntos como más importantes que otros.

- La objetividad constituye también un principio sujeto a múltiples y encontradas interpretaciones. Es preciso delimitar su contenido, particularmente con referencia a otros dos principios con los que frecuentemente se confunde: la veracidad y la neutralidad. La veracidad de la información sólo puede predicarse en el caso de los hechos, nunca a la hora de establecer opiniones. Como afirmaba el Tribunal Supremo de los Estados Unidos: «Bajo la $1 .^{a}$ Enmienda no existen falsas ideas» ${ }^{9}$. Los hechos pueden ser o no ciertos; las opiniones pueden ser medidas en función de su oportunidad o no, de su validez o invalidez, de su justeza o no, etc., pero nunca en función del principio de veracidad.

Algo similar ocurre con la neutralidad. La prensa no es un espejo, no refleja la realidad, sino que la filtra y la modela, al igual que un caleidoscopio modela y filtra la luz. Su función no es tanto la de actuar como correa de transmisión pasiva, cuanto intervenir como intérprete activo de lo que sucede en la sociedad. La información implica una actividad valorativa por parte de quienes la realizan. Ahora bien, la objetividad no se identifica ni con la neutralidad ni con la veracidad, pero debe fundamentarse en ellas.

Una de las tareas fundamentales exigibles a la objetividad informativa es la de tratar por todos los medios de reflejar la realidad social y evitar las constantes desviaciones, muchas de ellas consustanciales a la propia dinámica de los propios medios. He aqui, de acuerdo con McQuail, algunas de las desviaciones más corrientes —nos referimos al ámbito estricto de la información, y eludimos las que se producen en el marco más amplio de la comunicación, sobre todo de ficción - con respecto a la realidad ${ }^{10}$ :

- Sobrerrepresentación de las élites tanto como fuente de nacimiento de la información cuanto como objeto y contenido de la misma.

- Preeminencia de las informaciones «atípicas» tales como sucesos dramáticos, violentos o espectaculares, y que no se corresponden con la realidad ordinaria.

- Tratamiento sesgado en favor de los valores dominantes al seleccionar aspectos de una información.

- Tratamiento favorable, en el ámbito de la información internacional, a los países política, social o culturalmente más cercanos al propio.

${ }^{9}$ Citado por Santiago MuÑoz Machado, op. cit., p. 158.

${ }^{10}$ Denis McQuall, Mass Communication Theory, Londres, Sage, 1987, pp. 193-195. 
- Una menor presencia de las mujeres en cuanto objeto de la información, y en papeles o funciones mucho más limitados. (Una encuesta reciente del diario El País - 15.VI-88 - en relación a la frecuencia y papel de las mujeres en TVE, confirma plenamente esta regla.)

- Un tratamiento diferencial, claramente desfavorable, de las minorías, marginados, etc., extensible de modo particular a las minorías étnicas.

De ahí la necesidad imperiosa de establecer inputs con el objeto de que se produzca una adecuación más fiel y correcta entre la información que genera la sociedad y el tratamiento otorgado a la misma por parte de los medios de información.

- El último principio básico de la política informativa lo constituye la diversidad, que, al igual que lo que ocurre en otros casos, se refiere a dos ámbitos. De una parte, la posibilidad de que existan medios de información diversos; y, de la otra, que la información emanada de los medios existentes refleje la diversidad social, religiosa, política, cultural, étnica, etc., existente en el seno de la propia sociedad.

Ya indicábamos más arriba que una de las características de los medios de información actualmente vigente la constituye precisamente su uniformidad, y señalábamos asimismo que tal uniformidad suponía uno de los aspectos más negativos no sólo del vigente sistema informativo, sino incluso en la perspectiva del futuro inmediato, dada la progresiva concentración de los medios de información en manos de poderosos monopolios.

No caben soluciones voluntaristas ni angelicales a la hora de tratar de hacer efectiva la diversidad en la política informativa. La solución a tal problema es fundamentalmente práctica y tiene un nombre clave que se llama participación. Tanto la teoría de la libre información como la de la responsabilidad social han fracasado en grado importante a la hora de establecer una política informativa adecuada. Y la razón fundamental de tal fracaso radica en el hecho de que se ha convertido la información, como ya indicábamos al principio de este trabajo, en un juego dialéctico entre poderes. Si la vigente sociedad corporativa está originando, como acertadamente indica Salvador Giner, una marginación de quienes no satisfacen los requisitos del bomo corporativus, en sus diversas especies ${ }^{11}$, tal marginación alcanza niveles alarmantes en el ámbito concreto de la información. En efecto, la concentración de los medios de información en manos de poderosos monopolios, de una parte, y la unilinealidad de tal información, por la otra, reduce a una amplia mayoría de los ciudadanos a la categoría de marginales, de receptores pasivos sin capacidad alguna, ni de generar información, ni de contrarrestar la información recibida. El ciudadano, que es quien teóricamente constituye no ya el destinatario, sino incluso la propia razón de ser de la información, queda

"Véase Salvador Giner, Ensayos Civiles, Barcelona, Ediciones Península, 1987. En relación concreta al análisis de la corporatización de la sociedad, véase su excelente cap. 3 : «Clase, poder y privilegio en la sociedad corporativa», pp. 79 y ss. 
no sólo marginado, sino instrumentalizado en función de los intereses y fines perseguidos por los diversos centros de poder.

La única alternativa a esta solución radica en la necesidad de que se rompa esa situación de endogamia entre el poder político y los medios de comunicación y se estructure todo el sistema informativo en torno a tres grandes vértices o columnas, a saber: el poder político, los medios informativos y el conjunto de los ciudadanos.

La tarea va a resultar muy ardua y difícil, y el panorama que nos ofrece el futuro, a corto y medio plazo, no es precisamente alentador. A pesar de ello existen instrumentos cuya utilización por parte de los ciudadanos puede resultar menos complicada de lo que a primera vista parece. A algunos de estos instrumentos vamos a referirnos, sin ningún ánimo de exhaustividad, a continuación.

\section{b) Algunos instrumentos de control de la información}

Hemos hecho referencia, a lo largo de nuestro trabajo, a la transnacionalización e incluso mundialización del sistema informativo como consecuencia del surgimiento de las nuevas tecnologías. Es evidente que se está generando un nuevo sistema informativo y que ello conlleva la necesidad de estructurar un nuevo orden jurídico regulador del mismo a escala planetaria. A este nivel, los ciudadanos podemos jugar un papel importante, aunque menor que en niveles inferiores, como tendremos oportunidad de reseñar luego.

El importante grado de «tribalización» en el que se desenvuelve todavía el orden jurídico internacional favorece la acción incontrolada o semiincontrolada de los grandes monopolios transnacionales. No es precisamente casual que la mayor parte de los acuerdos alcanzados a nivel tanto europeo como internacional (Unión Internacional de Comunicaciones, INTELSAT, EUTELSAT, Agencia Espacial Europea, etc.) se refieran, de forma casi exclusiva, a aspectos, contenidos y medidas de estricto carácter tecnológico, provocando así una clara y grave situación de desventaja con respecto a la ordenación de los aspectos políticos, sociales y culturales relativos al nuevo orden informativo. Resulta mucho más importante para los intereses de los grandes monopolios la regulación de los campos de colaboración, o al menos de no injerencia mutua, que la fijación de criterios éticos o jurídicos relativos al contenido de la información.

Por ello, los ciudadanos deben tomar conciencia y exigir a los poderes públicos la adopción de medidas tendentes a una ordenación adecuada y correcta de la información, con particular incidencia en la necesidad de establecer fuertes medidas de control (normas antimonopolio, códigos internacionales de ética periodística, controles de calidad de la información, medidas tendentes a la protección de los derechos de los ciudadanos, especialmente en los aspectos que afectan a la intimidad personal, etc.). 
La creación de un nuevo orden jurídico internacional en el ámbito de la política de las comunicaciones -al igual que en otros muchos camposresulta absolutamente imprescindible, y en tal sentido es obligación de los ciudadanos denunciar el «provincialismo» en el que se desenvuelve la política de muchos Estados nacionales, particularmente europeos, que origina, en no pocas ocasiones, situaciones ciertamente ridículas, como ha sucedido recientemente en España con el lanzamiento del «Canal 10» en plena discusión parlamentaria «cuasi-decimonónica» acerca de la alternativa TV pública/TV privada. Si existe algún ámbito en el que la crisis del Estado-nación resulta manifiesta es, precisamente, en el de la comunicación ${ }^{12}$.

Aunque resulte paradójico y sorprendente, junto al proceso de concentración y universalización del sistema de comunicaciones, se está originando, de forma simultánea y paralela, un proceso de regionalización, entendido en el sentido de surgimiento y extensión de una amplísima y densa red de medios de comunicación de carácter regional o local, con autonomía tanto financiera como institucional con respecto a los grandes centros de información mundial. Uno de los ejemplos más espectaculares de tal extensión lo constituye la saturación de radios locales cuyo campo de cmisión se reduce a una determinada ciudad, o a una área geográfica reducida. Más recientemente se observa una tendencia similar a la creación de emisoras de televisión locales con las mismas características que en el caso de la radiodifusión.

La aparición y extensión de estos medios informativos no es casual y constituye una reacción lógica a la creciente despersonalización, estandarización y uniformidad de los grandes medios de comunicación. Los medios locales y regionales suponen un importante mecanismo de defensa frente a la influencia de los grandes monopolios, y devienen así en instrumento imprescindible para el mantenimiento de los valores específicos en los que se asienta la convivencia social de esas colectividades.

La revolución tecnológica va a favorecer de modo notable el desarrollo de tales medios, y va a permitir la aparición de nuevos sistemas informativos, tales como los vídeos comunitarios, los sistemas de televisión por cable a escala local, los periódicos no ya sólo locales o regionales, sino incluso hojas informativas de barrios, las radios y las TV piratas, los micro-media en zonas rurales, y un largo etcétera. No se precisan grandes medios financieros para su instalación y funcionamiento, y son susceptibles de una autofinanciación relativamente cómoda, particularmente a través de ingresos por publicidad de las firmas comerciales de carácter local, las cuales, mediante el pago de cantidades modestas, encuentran un excelente canal de difusión de sus productos.

Una de las características más importantes de tales medios informativos radica en su amplio margen de autonomía no sólo financiera e institucional,

12 Para una crítica global a la idea del Estado-Nación, véase Gurutz Jáuregur, Contra el Estado-Nación, Madrid, Siglo XXI, 1986. 
sino incluso en el ámbito estrictamente informativo, que es aquel en el que la dependencia con respecto a los grandes centros de poder es más manifiesta. En efecto, aun cuando en lo referente a la comunicación no estrictamente informativa, particularmente los programas de ficción, films, teleseries, etc., la dependencia con respecto a las grandes multinacionales va a seguir siendo muy importante, tal influencia se reduce de modo notable en el ámbito estrictamente informativo, ya que, por las propias características de tales medios, el contenido fundamental de la actividad informativa (noticias, reportajes, mesas redondas, entrevistas, etc.) tiene un carácter marcadamente regional o local, y se genera en el propio centro informativo local. No debe olvidarse que el ingrediente principal de los medios de comunicación lo constituye la información, la difusión de noticias. Las noticias suponen la actividad central a través de la cual se definen profesionalmente una gran parte de los periodistas.

Otra de las grandes ventajas de tales medios radica en la cercanía a sus receptores o destinatarios, lo cual implica un mejor conocimiento de la realidad en que se desenvuelve esa determinada colectividad (sus problemas, aspiraciones, idiosincrasia, etc.) y que origina, como consecuencia lógica, una mayor atención a tal realidad, un mejor acercamiento a la misma y, en definitiva, un importante grado de identificación entre emisor y receptor. Los medios de comunicación se ven obligados a realizar una auténtica política informativa de grass-roots en la que los problemas ordinarios y diarios de los ciudadanos se convierten en la estrella de la información.

En este mismo orden de cosas, los medios de comunicación de carácter local se hallan sometidos a un control social mucho más estrecho por parte de los receptores de la información, entre otras razones por la mayor facilidad existente para establecer e institucionalizar sistemas específicos de control. Pero, aun en el supuesto de una ausencia total de controles institucionales específicos, los medios locales y regionales se hallan mucho más condicionados por la propia presión social de la colectividad o comunidad en la que se asientan y realizan su actividad informativa. Los periodistas y los propietarios de los medios de información local conviven en ámbitos geográficos reducidos con los propios destinatarios de la información, su actividad profesional es objeto de comentarios, críticas, indicaciones, etc., por parte de personas con las que tienen que relacionarse y convivir físicamente. Ello implica, además de un mejor conocimiento de la realidad, un importante elemento de control en cuanto a la objetividad, calidad, etc., de toda la actividad informativa y una mejora sustancial de los procesos de feedback.

Otro de los aspectos positivos derivados de los medios de información locales y regionales radica en una disminución importante del factor de unilinealidad, que, como ya se indicó más arriba, constituye uno de los elementos más negativos del vigente sistema informativo. Si bien es cierto que muy difícilmente se conseguirá una total equiparación entre flujos descendentes y 
ascendentes, sin embargo, la importancia de los inpouts resultará mucho mayor que en los otros medios de información. La posibilidad de comunicación activa de un grupo de personas está en función del número que lo componen. Seis, diez o doce personas pueden expresar activamente todas sus opiniones sobre un tema concreto en un plazo prudencial de una o dos horas. Cincuenta personas necesitan muchísimo más tiempo, y no digamos nada en el caso de miles o millones de personas. Las posibilidades de una comunicación activa aumentan considerablemente en función de la reducción del número de participantes.

Los medios de comunicación locales o regionales constituyen, asimismo, elemento imprescindible para el desarrollo de la diversidad. Los individuos, o los grupos minoritarios, tienen un acceso más fácil a los mismos, bien constituyendo objeto de su atención, bien participando en sus programas, o bien, incluso, creando medios propios dirigidos a la salvaguarda de su propia idiosincrasia y de sus intereses específicos. De ahí que, desde una perspectiva normativa, los controles jurídicos de carácter normativo para regular la existencia de este tipo de medios deben de ser los mínimos posibles, facilitando así el acceso del mayor número posible de individuos y colectividades a la información, a través de la creación de medios propios, con la única limitación del respeto de la actividad de los otros medios, y del respeto de los derechos y libertades de los ciudadanos, particularmente en lo referente a la intimidad personal.

Tal como indicábamos más arriba, la revolución tecnológica no tiene por qué suponer, necesariamente, un factor negativo en orden al desarrollo de la participación de los ciudadanos en la vida social, política y cultural. Ahora bien, el determinismo tecnológico puede adquirir caracteres tanto negativos como positivos. Y tan perjudicial como la visión pesimista puede resultar una visión excesivamente optimista de los cambios que se nos anuncian. Con respecto al tema concreto del desarrollo de los medios de comunicación locales y regionales, resulta evidente que pueden constituir un instrumento de primer orden para la extensión y profundización de la democracia, sobre todo mediante una mayor participación política de los ciudadanos ${ }^{13}$. Ahora bien, en contra de lo afirmado por algunos futuristas optimistas como Alvin Toffler, etcétera, el cambio tecnológico puede aumentar la cantidad y calidad de la participación política; puede, asimismo, mitigar las desigualdades de participación existentes entre los diferentes grupos sociales; pero también puede no

${ }^{13} \mathrm{~F}$. Christopher Arterton ha analizado recientemente trece experimentos en en los que se han llevado a la practica actividades o proyectos concretos de teleparticipación. Se trata, en todos los casos, de experiencias muy concretas y que afectan a territorios reducidos, o bien a problemas $O$ aspectos muy específicos, todos ellos en el ámbito territorial de EE.UU. La muestra es muy variada y recoge experiencias llevadas a cabo en Alaska, Washington, Berks (en Reading.Pensylvania), Nueva York, Desmoines (Iowa), Hawai, Honolulú, Carolina del Norte, Ohio, etc. Sus conclusiones pueden verse en pp. 284 y ss. F. Christopher Arterton, Can Technology protect Democracy?, Londres, Sage Publications, 1987. 
hacerlo. El cambio tecnológico no supone en sí un aumento, ni tiene por qué suponerlo, de participación política, ni tampoco tiene por qué producir una inevitable transición de las instituciones políticas hacia una democracia directa o incluso hacia una democracia más participativa. Todo depende de nuestra actitud ante el cambio tecnológico y del uso que realicemos de esos nuevos instrumentos.

Para terminar, es preciso aludir a los medios de información clásicos cuyo prototipo y arquetipo lo constituyen, de un lado, la prensa escrita de ámbito estatal-nacional y, del otro, la radiotelevisión asentada en el mismo ámbito. Se ha dicho, quizá con un exceso de alegría, que estos medios se hallan en crisis. En el supuesto de que ello fuera cierto, lo cual se halla muy lejos de coincidir con la realidad diaria, el concepto crisis no significa, necesariamente, debilitamiento o desaparición, sino simplemente transformación con el objeto de adecuarse a las nuevas situaciones generadas por los cambios tecnológicos, sociales, económicos, políticos, etc. En todo caso, no hay duda alguna de que, por el momento, siguen constituyendo la columna vertebral del sistema informativo, hasta tanto se produzca un mayor desarrollo de los nuevos medios de comunicación.

Un tratamiento exhaustivo de su compleja problemática (dialéctica TV pública/TV privada; autonomía de los profesionales del medio con respecto tanto del poder político como de los propietarios; los problemas derivados de la cláusula de conciencia; el secreto profesional; los límites de la información - honor e intimidad personal, secretos militares, materias reservadas, etcétera-) supera el marco limitado y mucho más modesto del presente trabajo. Tan sólo quisiéramos hacer referencia a lo que, en nuestra opinión, constituye una de las mayores deficiencias de tales medios, incluso de aquellos que han alcanzado inestimables cotas de objetividad y calidad informativa. Se trata de la ausencia de participación de los receptores de la información, que generalmente queda reducida, en el mejor de los casos, a la publicación de un número muy escaso de cartas al director.

La calidad de la información juega un papel de primer orden, como argumento de convicción de los profesionales de la información, en esa lucha diaria por salvaguardar su propia autonomía frente a la jerarquía del resto de la corporación. Con ser ello extraordinariamente positivo, tal celo profesional puede provocar efectos contraproducentes. Se corre el peligro de una excesiva elitización o, si se quiere, profesionalización del medio, con todos los problemas que ello genera en cuanto a tecnocratización, aparición de procesos de feedback negativos, etc.

La única respuesta a tal peligro la constituye la institucionalización de la participación de los representantes de los usuarios (particularmente colectivos, representantes de usuarios individuales, tales como asociaciones de consumidores, etc.), y tal participación debe darse en un doble sentido: a) en el ámbito de la propia investigación de las comunicaciones; y $b$ ) en los propios 
medios de comunicación. La presencia activa de los usuarios de los medios, mediante participación en programas de radio o televisión, o mediante la publicación de artículos de opinión en la prensa escrita, aun a costa de la calidad del propio medio informativo, pueden constituir factor fundamental de favorecimiento de esos grande:; valores y principios por los que se deben regir los medios de comunicación y a los que ya se ha aludido más arriba. Es ésta una de las vías fundamentales para hacer posible el paso de la vigente relación bilateral medios de información/poder político, a una relación triangular medios de información/ciudadanos/poder político. 